\title{
'Precinct Planning and Design Standards (PPDS) in a coastal area': the development, planning and design process of a medium-sized coastal precinct incorporating community facilities and infrastructure
}

\author{
R. Moore \\ The Centre for Sustainable Design, School of Geography, \\ Planning and Architecture, University of Queensland, Australia
}

\begin{abstract}
This paper reviews a pilot study report on the planning and design process for a medium-sized mixed use coastal precinct. The development known as the Noosa North Shore Eco Tourism Portal is located in Queensland Australia. It was chosen to consider how a precinct planning and design standard might be employed to meet a need for a tool that gives consideration to a perception, that where sustainability principles are being applied there needs to be a means by which the outcomes of such drivers can be benchmarked and certified as industry best practice for ecological performances.

Also considered is the role of a planning and design standard and what are its goals, aims and objectives and how do they translate into those of development? How will the standard reflect the needs of developer and stakeholders involved in the provision of these types of precinct? It also comments on the process of benchmarking and certification of a development and how this will impact on the planning and design inputs required in satisfying third party criteria? The conclusion is a consideration of some of the major lessons to be taken from the pilot study regarding key focus areas in the development of a Precinct Planning and Design Standard (PPDS).

Keywords: human and natural environment, precincts, planning and design guidelines, sustainability, indicators.
\end{abstract}




\section{Introduction}

What follows is the assessment of the planning and design process of a coastal tourism precinct which incorporates mixed use travel and tourism facilities and infrastructure. The medium-sized precinct known as Noosa North Shore Eco Tourism Portal (the Development) [1] was offered by the Developer as a vehicle for consideration of how their ecological objectives are being translated into the development. The Development has also been benchmarked and certified by Green Globe an International Certification Organisation using its Precinct Planning and Design Standard (PPDS) [2].

PPDS is a process based ecological performance tool. Its structure and content, particularly the indicators and measures, have been developed to allow for its use on precinct developments where the perception is that environmental, social and economic sustainability principles are being applied. There needs to be in these situations a means by which the outcomes of such drivers can be benchmarked and certified as industry best practice for ecological performance. PPDS is a response to this need for an integrated and comprehensive framework within which developers, their planners and designers can achieve sustainable outcomes. The Development was considered an appropriate pilot study for PPDS given the nature, location and size of project. It was felt that important data and reflections would be gained from the study that would benefit not only the Developer but also the development industry at large. The study and benchmarking of the Development began in 2005 to consider how the Developer responded to an extensive sustainability agenda brought on by the ecological sensitivity of the site. Important questions for the Developer included:

- What were the critical areas of environmental, social and economic activity in the developments planning and design process and how did they and their advisors respond to them?

- What were the major planning and design decisions taken to achieve the Developers and other stakeholder's primary goals, aims and objectives?

\section{Background: a special place in a coastal area}

The Development is on the Noosa Shire Sunshine Coast in Queensland at the southern entrance to the world heritage Great Sandy Region. It is noted as a special place within this wilderness setting of Noosa's North Shore not least by the original inhabitants the Gubbi Gubbi People with whom a cultural heritage management plan is in place. The proposed regeneration and new development covers an area of 100 hectares and will consist of visitor accommodation, a leisure centre and associated facilities and a conservation area.

The North Site is the location of the existing North Shore Retreat. It will accommodate a range of new and existing facilities many of which are to be refurbished. Eventual an Eco Centre, a pub, convenience shop, and a conference venue will become the discernable centre of the resort. Some 200 beds in the form of cottages and apartment accommodation, capacity for 300 camping and caravan 'beds' and an Equestrian centre with access to horse trails are also planned. 
The South Site which has been subject to considerable ecological damage due to current and historic land use will provide some 30 hectares dedicated as National Park. Within the remainder of this site it is proposed to create conservation zones with limited and controlled public access. Residential provision known as Beach Road Holiday Homes will be in the form of low density eco lodges. On completion the development is expected to accommodate a maximum occupancy of some 482 persons.

\section{PPDS goals, aims and objectives}

The overall goal of the Green Globe Precinct Planning \& Design (PPDS) Standard is to facilitate environmentally sustainable planning, design and infrastructure construction of travel and tourism developments. Its key supporting aims and objectives are to:

- Provide developers with the fundamental guidelines for facilitating responsible and environmentally and socially sustainable planning, design and infrastructure construction from the initial design stage;

- Assist State and Local Authorities with the assessment process of medium to large mixed use precincts;

- Provide developers with an assessment of their performance, and encourage continual improvement;

- Provide consumers and travelers with the means to recognize and choose sustainable travel and tourism operations;

- Protect local ecosystems and the global environment, through realizing best practice planning, design and infrastructure construction procedures that minimize environmental impacts;

- Design for healthy and natural living in a range of contexts and for a variety of future customers;

- Provide facilities that have educational, health and technological benefits for guests and employees;

- Improve profitability through reduction in waste and energy savings.

\section{Key area indicators and measure's underlying the PPDS}

There are 11 indicators using 50 measures underlying PPDS Key Areas. An indicator is supported by on average four measures which are fully described in documents made available to Developers. The primary source of information is the PPDS Handbook which includes examples of guidelines, compliance tables and actual case study material.

\subsection{The key area sector benchmarking indicators are as follows:}

\subsubsection{Sustainable Master Planning Approach}

This key area indicator and its measures are concerned with project aims, goals and scope with respect to sustainability.

\subsubsection{Precinct location and siting planning}

- This key area indicator and its measures major on the precincts location with respect to regional services and infrastructure and its bearing on 
environmental impact in terms of resource use - energy, water, waste and transportation.

\subsubsection{Social commitment 'Quality of Life' approach}

- This key area indicator and its measures reviews the physical and soft policies seen as being essential to the creation of a sustainable community leading to an improvement or maintenance of 'Quality of Life' (with 'Quality of Life' meaning a shared vision of the future for the whole community).

\subsubsection{Energy efficiency and conservation}

- This key area indicator and measures consider the Developers 'whole of systems' view and approach during master planning the principle of sustainable energy design.

\subsubsection{Water conservation and management}

- This key area indicator and its measures are designed to consider the minimization of water usage and on site water treatment prior to use.

\subsubsection{Solid and other waste management}

- This key area indicator seeks to measure reductions of development infrastructure, building and operational waste.

\subsubsection{Resource conservation (materials)}

- This key area indicator and its measures consider the reduction of new materials and the use of reclaimed, recycled, and green materials.

\subsubsection{Chemical use}

- This key area indicator and measures review the Chemical Use Strategy of a precinct and aids in the identification and setting of targets for use of biodegradable alternative.

\subsubsection{Wastewater management}

- This key area indicator and its measures seek to consider the management and treatment of wastewater in such a way that treatment requirements are reduced in terms of tankage, energy and chemical requirements, and that treated wastewater is able to be reused for nonpotable uses.

\subsubsection{Storm water management}

- This key area indicator and its measures encourage and reward the idea of the environmental sustainability in terms of dealing with stormwater generated in the Precinct as opposed to discharging it for treatment elsewhere.

\subsubsection{Economic commitment}

- This key area indicator and measures seek to review the Developers approach in terms of positive inward investment, business opportunity and economic equity. 


\section{Planning and design inputs satisfying third party criteria}

\subsubsection{Sustainability Master Planning Approach}

The initial major influences on the precincts Sustainable Master Planning Approach were:

- The Developers overview of the primary sustainability planning and design aims and objectives;

- The protection of Noosa North Shore's natural attributes its character and its open space roles;

- The absorbing of impacts that would otherwise place pressure on the Great Sandy National Park and other fragile areas of wilderness on Noosa's North Shore;

- Providing a nodal point for visitor accommodation and services;

- Contributing to better opportunities for interpretation and education of visitors.

In responding to these influences the development has benefited from:

- Clear economic, social and environmental sustainable goals and vision integrated into the design brief;

- Sustainable urban design processes involving long term community participation;

- 'Enquiry by Design' workshops;

- 'Added Value' approach and Long term commitment of the Developer;

- 'Triple Bottom Line' principles implicit in development processes;

- A corporate culture and dedication to creating 'healthy, happy communities through careful site selection with recognition given to the enhancing of environmental and natural features, best practice urban design, and creative endeavor';

- A track record of innovation in the delivery of precincts;

- A corporate 'Sustainable Development Mission Statement';

- Clearly aligned sustainability targets and desired outcomes with PPDS;

- A highly skilled, multi disciplinary and integrated Design Team;

- Specific policy documents ensuring correct interpretation and compliance i.e. the 'Noosa North Shore Eco Tourism Portal Development Code';

- An 'Environnemental Management Plan’ (EMP);

- Establishment of a set of 'Environmental Sustainable Development' (ESD) related goals to assist in aligning development outcomes with business principles;

- Sustainability design targets and good project management procedures;

- The development of specific policy performance based documents ensures correct interpretation and compliance of the precinct's sustainability agenda;

- A sustainable infrastructure construction process management system prepared i.e. the 'Construction Environmental Management Plan'; (CEMP)

- A strategy for ongoing monitoring and environmental performance appraisals to ensure continuing improvement. 
The influences and benefits are reflected in the planned:

- Visitor accommodation across a spectrum of styles and affordability;

- Services to visitors that are consistent with the needs of accommodated guests and the passing public;

- Interpretive, educative and management functions that build on the site's location and setting.

The Development has committed to:

- Adopting best practice environmental management techniques;

- Integration with the site's landform and landscape, respecting and responding to its location and setting;

- The creation of a community that reflect the uniqueness of a community and its environment.

\subsubsection{Precinct location and siting planning}

The site has benefited from the following:

- A unique eco-tourism destination with a beach focus;

- A comprehensive development of the site;

- A regional and local stakeholder perspective;

- The environmental enhancement of existing landscaping and infrastructure;

- A strategy of sustainable environmental design for all new buildings.

Evaluation of the precincts location and resultant master plan zoning clearly indicates the potential of positive impacts on native habitat and biodiversity. This is due to the following:

- Total impermeable site coverage at the Development as a ratio is extremely low;

- Considerable conservation areas and non building zones;

- Extensive infrastructure planting and regeneration is envisaged;

- A flora and fauna resources philosophy for the Development;

- Native plant species are being encouraged for the re-establishment of previous landscaping character;

- The creation of increased public open space;

- Implementation of microclimate control strategies;

- Mitigation of heat island effects strategy to be implemented;

- Minimal site changes to the topography and natural environment;

- Added value use of "prime location views" from parts of the site;

- Individual building locations and orientation for the South Site;

- Design and positioning of lodges subject to strict development code;

- Extensive footpath and track provision within the development;

- Limited vehicle access and vehicle speed restrictions throughout site;

- Proposed own bus service.

\subsubsection{Social commitment "Quality of Life" approach}

The Development has specific socio economic goals i.e. eco tourist portal living which translates as:

- Quiet and relaxed holidaying in peaceful locations;

- Access to a range of sea and land based sports or recreational activities; 
- Short 'Seachange' based on a temporary community lifestyle;

- A diverse range of facilities and opportunities;

- Challenges and new experiences based in managed 'wilderness' settings.

Community 'social capital' dividends provided by the development include:

- Affordable travel and tourism opportunities;

- A free shuttle bus service from the ferry to the beach;

- A patrolled surf beach;

- Possible provision of water borne ferry connection to Noosa (the main tourist area);

- A visitor interpretive centre, incorporating the National Parks and Wildlife office;

- A shared bicycle and pedestrian path from the ferry to the beach;

- Closure for the community on the question of development with an end to the ongoing litigation over past development proposals;

- A clear consultation strategy for continuing engagement of stakeholders;

- Respect for local traditions and customs;

- A website based information site.

\subsubsection{Energy efficiency and conservation}

Energy savings are seen as being an issue of controlling development supply and use. The Development benefits from the following:

- A commitment to the target of at least $50 \%$ of the power supplied to the project from 'green' power sources.

- Targets being set for refurbished commercial and new buildings;

- Target reductions in the dependency and use of these resources for the new short stay eco lodges;

- Architects to ensure that energy consumption during construction and operation of the buildings is minimized.

- Eco-cabin design to reflect existing site constraints of topography, vegetation and natural features;

- Basic energy efficiency principles and construction material selections in compliance with provisions of the Building Code of Australia.

- Energy design strategy based on the Queensland Governments 'smarthousing' programme;

- Low density and lot sizes used to exploit an improved solar access profile.

Other areas that are being actively pursued in the designs for the South Site residential housing include:

- Passive design approaches i.e. natural and energy efficient lighting;

- External Shading (summer sun);

- Use of highly energy efficient water heating (alternative to standard electric);

- Thermal efficiency - passive heating and cooling, linked to more efficient use of natural ventilation (cooling), and reduced requirements for artificial internal heating (HVAC); 
- Where they are required, ensure choice of appropriate HVAC systems to maximize efficiency;

\subsubsection{Water conservation and management}

To overcome the non-availability of mains potable water supply strategies have determined that:

- An agreed target of $98 \%$ potable water self-sufficiency;

- A High value be placed on security and quality of supply;

- Specific targets set for reductions in the water supplied or consumed;

- A Development Code strategy for construction water usage;

\subsubsection{Solid and other waste management}

The developments location has determined that:

- A solid waste management strategy developed;

- On-site waste disposal and efficient appliances strategy developed;

- Reduction of construction waste generation targets to be set;

- Prefabrication and standardization considered during design phase;

- Solid waste generation reduction targets for construction and post occupancy stages to be set.

\subsubsection{Resource conservation (materials)}

The Developer has given considerable thought to the issue of sustainable materials by:

- 'Briefs' providing clear guidance on matters of selection and use;

- Targets set through the use of materials selection recommendations.

\subsubsection{Chemical use}

Two major strategies are being implemented at the development;

- A set target of $50 \%$ biodegradable chemicals use for cleaning chemicals, pesticides, and herbicides;

- No soil fertilization by chemicals at the development allowed.

\subsubsection{Wastewater management}

Targets at the development include the following:

- No waste water will be discharged from the development;

- An on-site sewage treatment plant to process all waste water;

- Effluent will be treated to tertiary standard;

- Partially recycling of grey-water for toilet flushing;

- Remainder of recycled grey-water to be dispersed through sub-soil irrigation in open space recreation areas;

Due to the importance of control of odor and insect activity two other matters require noting under this heading they are:

- An environmentally sensitive program regarding mosquitoes control so as to ensure optimum visitor experience within prescribed ecological guidelines.

- An Equine waste management system is already in place, utilizing offsite disposal and recycling in line with equine industry best practice. 


\subsubsection{Stormwater management}

Site sensitivity required that sustainable solutions be implemented these are to include the following:

- Short/ long term strategies developed i.e. the site will not be fertilized;

- Protection of existing qualities of the receiving surfaces;

- A comprehensive "Stormwater Management Plan (SMP) prepared;

- Majority of rainfall on the site onto natural landscape;

- Replenishing of existing wetlands and/or groundwater table;

- Runoff from roof areas will generally be collected in tanks for reuse;

- Potential source of contaminants strategy implemented i.e. runoff from road surfaces minimized by low traffic volumes;

- 'Bio Filtration' systems for areas of the precinct;

- Rock lined drains to collect stormwater runoff for diversion to water collection dam which is to be used as a supply of non-potable water.

\subsubsection{Economic commitment}

The Developments economic commitment to its community, local area and region include the following:

- Recognition given to the importance of the local business community being engaged in a partnership including active participation in the 'Enquiry by Design' process;

- Engagement of local operators to assist in the regulatory process;

- Approximately 75 to 100 part-time construction related jobs generated during construction phase;

- Creation of new business and service opportunities providing new and improved facilities such as a convenience store, a café and restaurant;

- A research base for scientific studies linked to the Great Sandy Region;

- An increase in the business base along with improvement in the viability of the existing businesses in the area of the development;

- Increased potential spending power within the precinct;

- Predicted 30 to 50 permanent employment opportunities;

- Possible indirect full-time positions arising from the related businesses;

- A direct economic contribution to the region of up to $\$ 5$ to $\$ 10$ million dollars per annum;

- Economic equity via a wide range of affordable accommodation;

- Training programmes regarding environmental and social linked job opportunities for dedicated support parks and wildlife staff positions.

\section{Evaluation of indicators and measures}

Using an indicator evaluation matrix based on measures that reflect accepted good 'sustainable' practice the Development achieved 'Industry Best Practice' in 44 of the 50 measures noted in the case study matrix. Action is being taken to satisfy the requirements of at least a further 2 of these baseline measures. This achievement places Noosa Northshore Tourism Eco Portal at the forefront of sustainable precinct development. 


\section{Conclusions: lessons to be taken from the development}

The Developer challenged 'business as usual' process norms whilst recognizing that sustainable agendas require considerable inputs. The Eco Portal has achieved a high rating due in part to the Developer implementing an innovative delivery strategy and by their long term commitment and involvement with the precincts development and associated post operation management processes.

The Developer by showing a willingness to put forward a sustainable agenda of his own making has sought to recognize the relationships with clients, regulators, the public and suppliers. This agenda has resulted in a more effective and sustainable development process. The approach taken has resulted in a 'sustainable' response to the growing Australian demand for a 'sea change' leisure/active tourism based lifestyle growth in coastal regions.

The Developer also recognized that stakeholder communication would be critical to this development and that it takes many forms. Their response was to effectively encompass the total community by facilitating with great skill the 'Enquiry by Design' process. Discussions with the Developer have indicated a continuing role for assessment. This is a result of recognizing that many sustainable inputs and their impacts take place over time and may come about by adjustment to aspects of the development. The phenomenon will most likely be seen in the critical social and economic areas.

The power of specifically developed 'ecological performance' documents is seen in throughout the precincts planning and design development. For example the Development Code which seek to ensure compliance throughout the Development in terms of delivery and quality. The enshrining of the document and the commitment of a dedicated consultant to aid users will maintain an important link between the Developer, consultants, the building team, purchasers and other stakeholders.

The Developer responded to the demand for leisure/active tourism sought by many Australians and overseas visitors. If this demand is to be managed in a sustainable manner then it is without doubt that developments must be measured in terms of their impacts and eventual performance. Without the ensuing data, critical planning and design decisions cannot be made with any certainty of success. By their challenging the norms of precinct delivery and opening their planning and design to the scrutiny of a new standard they indicated a willingness to reduce if not mitigate entirely the impacts of development.

These actions and others that are noted suggest that for those who wish to undertake innovative, responsible and committed approaches on their developments they need at least to recognize the merits of an open mind in their approaches in seeking and achieving sustainable outcomes.

\section{References}

[1] R. Moore and J. Cameron - Pilot Study Noosa North Shore Eco Tourism Portal Noosa - Green Globe Queensland, Australia 2006.

[2] Hyde R, Moore R, etc., - The Green Globe Precinct Planning and Design Standard and Handbook - Green Globe Queensland, Australia 2005. 